\title{
Hyperuricemia in Renal patients: Treat or not to treat
}

\section{Muhammad Tanzeel Abbasi* Muhammad Rashid Asghar, Khuram Bashir and Muhammad Nauman Hashmi}

Consultant Nephrologist, Department of Nephrology, Multan institute of kidney diseases, Multan, Pakistan
Received: 16 July, 2021

Accepted: 05 August, 2021

Published: 06 August, 2021

*Corresponding author: Dr. Muhammad Tanzeel Abbasi, Consultant Nephrologist, Department of Nephrology, Multan institute of kidney diseases, Multan, Pakistan, Tel: 00923336106372;

E-mail: dr.tanzeel01@hotmail.com

Keywords: Hyperurecemia; CKD; Hemodialyis; Periotneal dialysis; Renal transplant

https://www.peertechzpublications.com

\section{Check for updates}

\begin{abstract}
Hyperuricemia management in chronic kidney disease is a challenging task. We encounter this dilemma on regular basis. Kidney disease patients have wide range (CKD population, Hemodialysis \& peritoneal dialysis cohort and renal transplant patients).

In clinical practice wide range of opinions exists. This dubious area intrigued us to look into it. Looking into available published data majority of studies are observational and few are randomized control trials. All studies favor that high uric acid level has accelerated effect on CKD progression. Controversy is on its management, whether by treating it we are able to slow down CKD progression or not. Data supports that CKD progression is not slowed down but needs more studies to give conclusive answer. In dialysis and renal transplant patients studies showed inverse relationship of high uric levels with all-cause mortality. However, in peritoneal dialysis data suggests linear relationship of hyperuricemia with mortality.
\end{abstract}

A pro as well as anti-oxidant effect of uric acid has been discussed in literature. Variable cut off for hyperuricemia has been used but more census is on 7 mg/dl. Symptomatic gout definitely needs uric acid lowering therapy but in asymptomatic hyperuricemia no conclusion so far. There is paucity of data in maintenance dialysis and renal transplant patients.

\section{Abbreviations}

CKD: Chronic Kidney Disease; GFR: Glomerular Filtration Rate; ESRD: End Stage Renal Disease; RAAS: Renin Angiotensin Aldosterone System; KDIGO: Kidney Disease Improving Global Outcome; PERL: Preventing Early Renal Loss; CKD-FIX: Slowing of Kidney Disease Progression from the Inhibition of Xanthine Oxidase; NSAID`s: Non-Steroidal Anti-Inflammatory Drugs; Focus: Febuxostat Open-Label Trial of Urate Lowering Efficacy and Safety.

\section{Introduction}

Uric acid is a breakdown product of purine metabolism. It was about two centuries ago when uric acid was first identified. For a long time, hyperuricemia and gout were considered two names of a single entity but with the passage of time, it is quite evident that hyperuricemia has a vast spectrum of metabolic and clinical presentations [1]. It can result either due to overproduction or reduced excretion of uric acid [2]. It is still indecisive that hyperuricemia has a protective or causative role in degenerative disorders of nervous system and renal as well as and cardiovascular illnesses [3]. Hyperuricemia is prevalent worldwide including both developed and underdeveloped countries [4]. Data of National Health and Nutrition examination survey of 2007 to 2016 shows $20 \%$ prevalence of hyperuricemia in US population.

Hyperuricemia is a frequent finding in Chronic Kidney Disease patients (CKD). Reduced Glomerular Filtration Rate (GFR) is responsible for reduced excretion of uric acid. Prevalence of hyperuricemia in advanced CKD patients is $60 \%$ [5,6]. Hyperuricemia and CKD have a strong correlation but details are still controversial. Previously, monsodium urate crystals were assumed to be a factor in pathogenesis of CKD [7]. However, recent literature highlights a direct involvement of soluble serum urate in pathogenesis and progression of CKD $[7,8]$.

Literature review shows an inverse relationship between high uric acid levels and mortality in End Stage Renal Disease (ESRD) patients undergoing hemodialysis [9]. Low uric acid levels were found to be associated with low all cause and cardiovascular mortality. However, in peritoneal dialysis 
patients, few studies have found a direct relationship of hyperuricemia with increased mortality but others have found no significant association [10]. Increased uric acid levels are also frequently observed in early post-transplant period. Although, there is an evidence of inverse association between hyperuricemia with mortality in transplant recipients but it is still inconclusive to establish a beneficial effect of treating asymptomatic hyperuricemia in this population [11].

There has been much debate about normal levels of uric acid so the definition of hyperuricemia is variably presented in literature. Practically, the definition of hyperuricemia is based on solubility of uric acid at physiological pH. Some studies have labelled hyperuricemia beyond a cut-off value $>7 \mathrm{mg} / \mathrm{dl}$ in males and $>6 \mathrm{mg} / \mathrm{dl}$ in females [12]. Another study by Desideri $\mathrm{G}$, et al. defined uric acid levels above $6 \mathrm{mg} / \mathrm{dl}$ as hyperuricemia [13]. Physiochemical definition of hyperuricemia seems logical and corresponds to uric acid levels beyond $7 \mathrm{md} / \mathrm{dl}$. Above this level, uric acid precipitates and may cause symptoms.

This review article is aimed to explore certain unanswered questions about impact of hyperuricemia on progression of CKD including dialysis and transplant patients.

\section{A. Pathophysiological basis of hyperuricemia}

Endogenous and exogenous purines are the sources of uric acid. Metabolism of purines mainly occurs in liver but some other tissues (intestines) which have xanthine oxidase enzyme activity, can also metabolize purines [14]. Uric acid is formed as end product of this metabolism. In animals, uric acid is further converted to allantoin by the activity of enzyme uricase [15]. Almost $2 / 3^{\text {rd }}$ of the uric acid is excreted by kidneys and remaining $1 / 3^{\text {rd }}$ by intestines [Figure 1]. In kidneys, filtration and secretion of uric acid are simultaneously carried out and $90 \%$ of the uric acid is ultimately reabsorbed.

Anti-oxidant activity of uric acid plays a fundamental role in tissue healing by initiating inflammatory cascade. Another basic function of uric acid is to remove nitrogenous wastes from body. Apart from these beneficial effects, uric acid has been found to be an independent predictor of increased cardiovascular mortality and also causes insulin resistance by increased production of oxygen species $[10,16]$.
Data has analyzed a contributing role of different transporter genes including $S L C 2 A 9, S L C 22 A 12$, and $A B C G 2$ in hyperuricemia and increased urate excretion. $A B C G 2$ gene was found to be a highest risk factor for gout. Dysfunction of ABCG2 gene has been highlighted as a strong predictor of either under excretion or over excretion of uric acid [17]. Alcohol consumption has remained a topic of discussion due to its association with hypertension. However, it is now surprising to know that increased uric acid level is an independent risk factor of hypertension. A study by Tatsumi Y, et al. is a breakthrough in establishing its role as an independent risk after excluding the effect of alcohol consumption [18].

Uric acid levels are indirectly proportional to decline in renal functions. Decreased excretion of uric acid at the expense of reduced GFR in CKD patients is the main reason of hyperuricemia.

\section{Pathogenesis of hyperuricemia induced renal damage}

Increased uric acid levels have a profound effect in new onset as well as in progression of pre-existing CKD. Almost $40 \%$ of CKD stage I-III patients have hyperuricemia while it is seen in $70 \%$ of CKD stage-IV and V patients [19]. The beneficial effects of treating hyperuricemia in CKD are still debatable. Various mechanisms of hyperuricemia induced renal damage have been discussed in literature [Figure 2]. Schlee $S$, et al. explained role of monosodium urate crystals deposition in renal tubules leading to tubular cast formation and obstructive nephropathy [20].

Apart from beneficial effects of anti-oxidant activity, uric acid also has a pro-oxidant effect once it is incorporated into renal cells. The resulting oxidative stress provokes free radical mediated DNA damage and apoptosis [21]. Uric acid upregulates Renin Angiotensin Aldosterone System (RAAS) and resulting endothelial damage due to RAAS activation is another mechanism of decline in GFR [22].

Fan S, et al. compiled data of about 1700 renal biopsies and evaluated correlation of biopsy findings with uric acid levels. It was quite surprising that hyperuricemia was strongly associated with segmental sclerosis, interstitial fibrosis and

\section{Tissue breakdown}

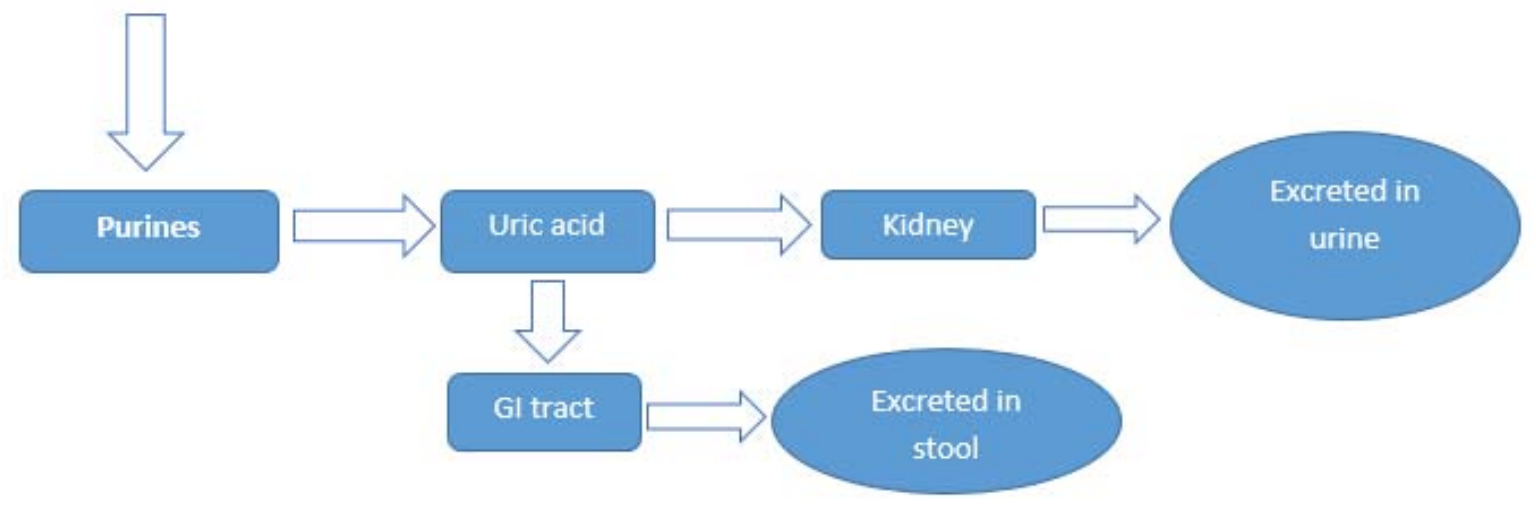

Citation: Abbasi MT, Asghar MR, Bashir K, Hashmi MN (2021) Hyperuricemia in Renal patients: Treat or not to treat. Arch Clin Nephrol 7(1): $050-056$. 


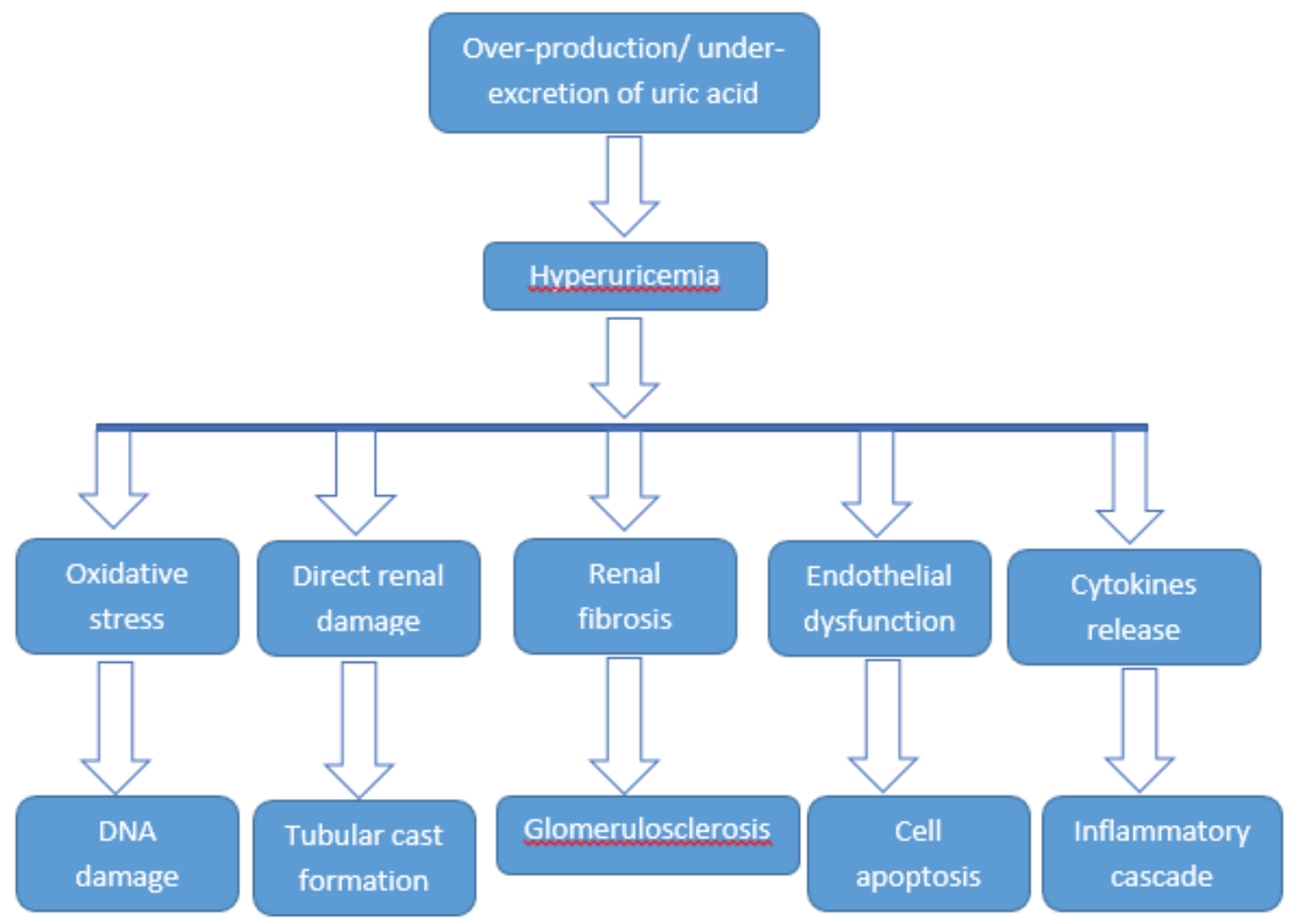

Figure 2: Mechanism of hyperuricemia associated renal damage.

tubular atrophy [23]. Another pattern of renal injury caused by hyperuricemia is glomerulosclerosis. Artherosclerosis of renal vessels and glomerular hypertension are the logical etiologies of glomerulosclerosis as explained by Richard J, et al. [24]. Hyperuricemia is also predominantly involved in inflammatory damage to renal parenchymal cells. Deposition of monosodium urate crystals has been found to mediate this process [25].

\section{Hyperuricemia and progression of CKD}

Hyperuricemia is a modifiable risk factor for CKD and owing to this fact, lots of efforts regarding dietry modifications and treatment strategies are in practice. Studies have documented a role of uric acid in development of incident CKD. Striking data by Zhu P, et al. have found a strong association of hyperuricemia and incident $\mathrm{CKD}$ in middle aged population irrespective of other metabolic risk factors [26].

There is no convincing data about when and how to treat hyperuricemia in CKD as well as dialysis and transplant recipients. Multiple observational studies have found a causative role of hyperuricemia in CKD progression. Srivastava, et al. recently established uric acid as an independent risk factor for renal failure in patients with early CKD but whether uric acid lowering strategies can help in retarding this progression remained inconclusive [27]. Kidney Disease Improving Global Outcome (KDIGO) guidelines have no strong recommendation for treating hyperuricemia in CKD population due to lack of consensus. These guidelines do not even confirm the role of hyperuricemia treatment in slowing progression of kidney disease [28].
Recently, a randomized controlled trial, Preventing Early Renal Loss (PERL trial) in type-I diabetic patients is a breakthrough in evaluating the impact of treating hyperuricemia in kidney diseases [29]. A total number of 267 patients were given allopurinol and were compared with 263 patients who were given placebo. Although, uric acid levels were effectively lowered but it was not found to lower the risk of disease progression. Another randomized controlled trial of Slowing of Kidney Disease Progression from the Inhibition of Xanthine Oxidase (CKD-FIX), published in New England journal of medicine also came out with similar results [30]. 185 patients received allopurinol as uric acid lowering treatment and were compared with 184 patients who received placebo. Again, the treatment was effective as uric acid lowering strategy but did not show any impact in slowing progression of disease. PERL and CKD-FIX trials are based on strong recommendations about the impact of treating high uric acid levels and its effect on disease severity.

Uric acid is also responsible for endothelial dysfunction but treating hyperuricemia does not improve endothelial damage. The reality of this effect was established in a double blind controlled trial by Borgi L, et al. [31]. The available data todate does not establish the role of treating hyperuricemia in effectively retarding progression of CKD. Further trials like PERL and CKD-FIX can help in providing a strong consensus about this fact.

\section{Correlation of CKD stages with uric acid level}

Since the mechanism of hyperuricemia also includes 
under-excretion of uric acid so, uric acid levels are variably increased in different stages of CKD based on GFR. Till date, uric acid levels beyond $7 \mathrm{mg} / \mathrm{dl}$ are considered as hyperuricemia irrespective of CKD presence or absence. There is lack of data about uric acid levels according to GFR. However, it is postulated that urate nephropathy can develop beyond certain cut-off values of serum creatinine [32]. Uric acid levels above $9 \mathrm{mg} / \mathrm{dl}$ in patients with serum creatinine of $1.5 \mathrm{mg} / \mathrm{dl}$ is high likely to cause urate nephropathy [Table 1].

A study by Qayyum $M$, et al. correlated high incidence of hyperuricemia in pre-dialysis CKD population with abnormal metabolic profile [33]. Although uric acid levels are gradually increased with decline in GFR but this increase is quite rapid in the presence of hyperlipidemia and smoking [34]. The maximum rise of uric acid levels is seen in patients with CKD stage 5 [Figure 3]. Further conclusive studies will be required to decide cut-off values for uric acid in different stage of CKD.

\section{B. Hyperuricemia in dialysis population}

Patients requiring hemodialysis or peritoneal dialysis, both are prone to develop hyperuricemia. Uric acid levels are variably reported in studies to define hyperuricemia in dialysis population. Mean uric acid levels above $7.5 \mathrm{mg} /$ $\mathrm{dl}$ in hemodialysis and above $8.5 \mathrm{mg} / \mathrm{dl}$ in peritoneal dialysis patients are considered abnormal [35,36]. This variability is probably based on prescription of dialysis and timings of sample collection.

In patients with standard hemodialysis prescription, high flux dialyzer can remove almost $70 \%$ of uric acid and in PD, 15$20 \mathrm{ml} / \mathrm{min}$ is removed based on peritoneal dialysate flow rate $[37,38]$. In a review article by Murea, et al. 9 out of 14 studies showed an inverse relationship of uric acid levels with all-cause mortality [14]. Rest of five studies found no association. This

Table 1: Uric acid levels in accordance with serum creatinine in pathogenesis of urate nephropathy.
Serum creatinine levels $(\mathrm{mg} / \mathrm{dl})$

Less than 1.5

$1.6-2.0$

More than 2

$$
14
$$

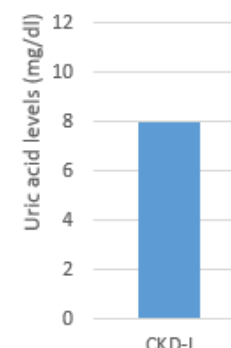

CKD-I

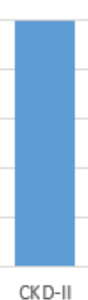

CKD-II
Serum uric acid levels $(\mathrm{mg} / \mathrm{dl})$

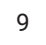

$9-10$

$>10$ was a surprising finding because it was contrary to pre-dialysis CKD population. The same finding has also been reported by Latif, et al. [39]. Different theories have been suggested for this finding in HD patients. It was postulated that uric acid is a marker of better nutrition so a low uric acid level can lead to increased mortality. However this opinion was later rejected because mortality was not reduced even after correction of nutritional parameters [40].

Regarding PD patients, only two of these studies found direst relationship of uric acid levels with mortality. This demands further research to document the role of higher uric acid levels in decreasing cardiovascular mortality.

Removal of uric acid in dialysate has a linear relationship with urea. Immediately after dialysis, uric acid levels will be markedly low compared to pre-dialysis levels. Therefore, timings of sample collection is important to explain the effect of dialysis on uric acid levels. Mean uric acid levels will be high between two dialysis sessions. Patients with high predialysis uric acid levels may have normal levels after dialysis which are sufficient to carry out anti-oxidant activity. This is another explanation of protective effect of hyperuricemia in HD patients [10].

\section{Hyperuricemia in kidney transplant recipients}

Hyperuricemia is commonly observed in early posttransplant period and can precipitate gout [41]. Cyclosporine has been found to have a significant role in hyperuricemia in transplant recipients. Almost $84 \%$ of patients treated with cyclosporine develop hyperuricemia while azathioprine and corticosteroids are responsible in $34 \%$ of cases [42]. Other possible causes include use of diuretics, acute tubular necrosis and episodes of graft rejection [43].

Effect of hyperuricemia on renal allograft has not been studied in detail and available data also remains inconclusive in evaluating its association [44]. Some studies have documented an inverse relationship of uric acid levels with graft function while other studies failed to find any association $[45,46]$.

Treatment of hyperuricemia and associated gouty attacks is not free of risks in transplant recipients. So, there is no current recommendation of its treatment and available literature also has conflicting results. However, it is proposed that management of modifiable risk factors including smoking and weight reduction is mandatory and if there is no response, dose reduction or complete avoidance of cyclosporine with suitable alternate option should be adopted [47].

\section{Management of hyperuricemia in CKD patients}

There is no sufficient data available to-date about effective role of treating hyperuricemia in chronic kidney disease. Most of the studies including recently published PERL and CKD-FIX trials have clearly documented no impact of lowering UA on CKD progression. However, efforts are routinely carried out to reduce UA levels in view of reducing associated cardiovascular mortality. In such conditions, treatment of hyperuricemia is considered an adjunct strategy in addition to definite management of co-morbid conditions [48].

Citation: Abbasi MT, Asghar MR, Bashir K, Hashmi MN (2021) Hyperuricemia in Renal patients: Treat or not to treat. Arch Clin Nephrol 7(1): 050-056. 


\section{E. Non-pharmacological management}

Life-style modification is almost equally effective to drug treatment in management of hyperuricemia but has a limited impact on progression of kidney disease. There is no convincing data recommending non-pharmacological management as an effective option. In CKD patients with asymptomatic hyperuricemia, there is no role of pharmacological and nonpharmacological management. However, following life style changes are recommended to reduce hyperuricemia associated risk factors other than kidney disease:

\section{- Reduction in purine rich diet}

- Weight reduction with modest increase in daily exercise (7kg weight loss can result in $1.5 \mathrm{mg} / \mathrm{dl}$ decline in uric acid levels) [49].

\section{- Decreased alcohol consumption}

- Limited use of drugs causing hyperuricemia like nonsteroidal anti-inflammatory drugs (NSAID`s), thiazide diuretics, beta blockers.

\section{Medical management}

There are three main classes of drugs including xanthine oxidase inhibitors, uricosuric drugs and recombinant uricase for treatment of hyperuricemia.

\section{a. Xanthine oxidase inhibitors}

Allopurinol is metabolized to oxypurinol which inhibits enzyme xanthine oxidase thus limiting the conversion of xanthine to uric acid. Febuxostat is a non-purine xanthine oxidase inhibitor. Both of these drugs do not disrupt synthesis of vital purines. Previous data about use of allopurinol suggests its efficacy in retarding progression of CKD as mentioned in a trial by Goicoechea, et al. in 2010 [50]. Another trial by Kao, et al. came out with the same results [51]. It has also been debated in literature that stopping allopurinol can provoke renal dysfunction in CKD patients who are already taking this medicine [52]. These trials had a small sample size but the results strongly recommended the use of allopurinol in CKD population. However, no significant improvement was reported in blood pressure and cardiovascular mortality.

Allopurinol needs dose adjustment in CKD patients based on GFR because it has renal excretion. Stevens-Johnson syndrome is a life-threatening side effect of allopurinol and is another major reason in reducing its dose. In order to minimize the risk of allergic reactions, starting dose of allopurinol should be 1.5 times the GFR. If the dose is tolerated for next eight weeks, then it can be increased till target UA level of $7 \mathrm{mg} / \mathrm{dl}$ or below is achieved. It should be avoided in transplant recipients taking azathioprine because conversion of 6 mercaptopurine to thiouric acid is catalyzed by enzyme xanthine oxidase. Inhibition of this enzyme by allopurinol will result in accumulation of 6 mercaptopurine causing azathioprine toxicity.

Febuxostat is more effective than allopurinol in inhibition of xanthine oxidase. Its excretion is through bile so no dose reduction is required in CKD patients. Focus trial (febuxostat open-label trial of Urate lowering efficacy and safety) showed a clear benefit of febuxostat in improving GFR [53]. Another study compared efficacy of febuxostat vs. allopurinol in 1086 CKD patients. The results of this study were also in favor of febuxostat in terms of GFR improvement [54]. Despite these results, a recent randomized trial by Kimura $\mathrm{K}$, et al. reported no benefit of febuxostat in improvement of renal functions in CKD patients with asymptomatic hyperuricemia [55]. Some studies have also reported increased mortality associated with febuxostat use in cardiac patients and do not suggest it as first line uric acid lowering therapy [56]. There are very few studies about febuxostat use in dialysis population so US Food and Drug Administration (FDA) has not approved its use in these patients.

\section{b. Uricosuric drugs}

Probenecid, sulfinpyrazone and benzbromarone increase uric acid excretion and are very effective as uric acid lowering agents in patients with normal renal functions. However, they are not approved for CKD patients and those with previous history of nephrolithiasis [57]. Sulfinpyrazone has documented interactions with cyclosporine and lowers its trough levels in transplant recipients. So, cyclosporine levels need close monitoring and dose adjustment accordingly.

Benzbromarone is also an effective first line uric acid lowering drug in patients with HLA-B*5801 allele. This allele is more prevalent in Asian population and these patients are prone to allopurinol toxicity [58]. Its use is also limited due to its hepatotoxic effects. Some other drugs including losartan, vitamin $\mathrm{C}$ and fenofibrates also have uricosuric properties but their use is confined to other systemic conditions [57]. Canakinumab is an interlekin-1 inhibitor and has been approved by European Union for the treatment of hyperuricemia and acute gout in patients with normal renal functions. In CKD and transplant patients, they still have an investigational role and are not approved so far.

\section{c. Recombinant uricase}

Pegloticase and rasburicase are recombinant uricase which are recently approved for treatment of symptomatic gout. It converts uric acid to a more soluble product, allantoin. It is given intravenously on alternate weeks in patients who are not responding to oral uric acid lowering medications. It can be given to CKD, dialysis and transplant patients [57]. Rasburicase is also being used in patients receiving cancer chemotherapy who are at risk of tumor lysis syndrome [59].

\section{Conclusion}

The relationship of hyperuricemia and decline in renal functions has been established in most of the observational studies. The mechanisms involved in pathogenesis of CKD have also been proposed in literature but there is no conclusive evidence so far. Treatment of symptomatic gout is required with uric acid lowering therapy in CKD patients but there are no current recommendation to treat asymptomatic hyperuricemia in this population. There is paucity of data in patients

Citation: Abbasi MT, Asghar MR, Bashir K, Hashmi MN (2021) Hyperuricemia in Renal patients: Treat or not to treat. Arch Clin Nephrol 7(1): 050-056. 
undergoing maintenance dialysis and in transplant recipients. Large randomized controlled trials are mandatory to develop a consensus approach in establishing a definite mechanism of hyperuricemia in disease progression and efficacy of its treatment in improving renal functions.

\section{References}

1. Stack A, Manolis AJ, Ritz E (2015) Detrimental role of hyperuricemia on the cardio-reno-vascular system. Curr Med Res Opin 3: 21-26. Link: https://bit.ly/3xlsec3

2. Dalbeth N, Merriman TR, Stamp LK (2016) Gout. Lancet 388: 2039-2052. Link https://bit.ly/3CanycZ

3. Kia DA, Noyce AJ, White J, Speed D, Nicolas A, et al. (2018) IPDGC collaborators, Burgess S, Lawlor DA, Davey Smith G, Singleton A, Nalls MA, Sofat R, Wood NW. Mendelian randomization study shows no causal relationship between circulating urate levels and Parkinson's disease. Ann Neurol 84: 191-199. Link: https://bit.ly/3yqc4zt

4. Smith E, March L (2021) Global Prevalence of Hyperuricemia: A Systematic Review of Population-Based Epidemiological Studies [abstract]. Arthritis Rheumatol 67. Link: https://bit.ly/37fZB5I

5. Cha RH, Kim SH, Bae EH, Yu M, Choi BS, et al. (2019) Physicians perceptions of asymptomatic hyperuricemia in patients with chronic kidney disease: A questionnaire survey. Kidney Res Clin Pract 38: 373-381. Link: https://bit.ly/3ipmjyJ

6. Eleftheriadis T, Golphinopoulos S, Pissas G, Stefanidis I (2017) Asymptomatic hyperuricemia and chronic kidney disease: Narrative review of a treatment controversial. J Adv Res 8: 555-560. Link: https://bit.ly/3yqcdD1

7. Johnson RJ, Nakagawa T, Jalal D, Sánchez-Lozada LG, Kang DH, et al. (2013) Uric acid and chronic kidney disease: which is chasing which? Nephrol Dial Transplant 28: 2221-2228. Link: https://bit.ly/3jiH2Dv

8. Crișan TO, Cleophas MC, Oosting M, Lemmers $\mathrm{H}$, Toenhake-Dijkstra $\mathrm{H}$, et al. (2016) Soluble uric acid primes TLR-induced proinflammatory cytokine production by human primary cells via inhibition of IL-1Ra. Ann Rheum Dis 75 755-762. Link: https://bit.ly/2WOznoN

9. Sugano N, Maruyama Y, Kidoguchi S, Ohno I, Wada A, et al. (2019) Effect of hyperuricemia and treatment for hyperuricemia in Japanese hemodialysis patients: A cohort study. PLoS One 14: e0217859. Link: https://bit.ly/3Ce2NwT

10. Rui B, Filipa C, Tiago P (2020) Hyperuricemia in Chronic Kidney Disease: a role yet to be explained. Portuguese Journal of Nephrology \& Hypertension 34. Link: https://bit.ly/3yrIARO

11. Weng SC, Tarng DC, Chen $Y C$, Wu MJ, \& on behalf of the CKDBHPDH investigators (2016) Febuxostat is superior to traditional urate-lowering agents in reducing the progression of kidney function in chronic kidney disease patients. Cogent Medicine 3: 1. Link: https://bit.ly/3lvlcj0

12. Mallat SG, Al Kattar S, Tanios BY, Jurjus A (2016) Hyperuricemia, Hypertension, and Chronic Kidney Disease: an Emerging Association. Curr Hypertens Rep 18 74. Link: https://bit.ly/3infAoJ

13. Desideri G, Castaldo G, Lombardi A, Mussap M, Testa A, et al. (2014) Is it time to revise the normal range of serum uric acid levels? Eur Rev Med Pharmacol Sci 18: 1295-1306. Link: https://bit.ly/2VpXrhn

14. Murea M, Tucker BM (2019) The physiology of uric acid and the impact of end-stage kidney disease and dialysis. Semin Dial 32: 47-57. Link: https://bit.ly/3ipnbDv

15. Sánchez-Lozada LG, Lanaspa MA, Cristóbal-García M, García-Arroyo F, Soto $V$, et al. (2012) Uric acid-induced endothelial dysfunction is associated with mitochondrial alterations and decreased intracellular ATP concentrations. Nephron Exp Nephrol 121: e71- e78. Link: https://bit.ly/3fvshMn
16. Oh TR, Choi HS, Kim CS, Bae EH, Ma SK, et al. (2019) Hyperuricemia has increased the risk of progression of chronic kidney disease: propensity score matching analysis from the KNOW-CKD study. Sci Rep 9: 6681. Link: https://bit.ly/3xnRrmc

17. Hoque KM, Dixon EE, Lewis RM, Allan J, Gamble GD, et al. (2020) The ABCG2 Q141K hyperuricemia and gout associated variant illuminates the physiology of human urate excretion. Nat Commun 11: 2767. Link: https://bit.ly/3lv2VSA

18. Tatsumi Y, Asayama K, Morimoto A, Satoh M, Sonoda N, et al. (2020) Hyperuricemia predicts the risk for developing hypertension independent of alcohol drinking status in men and women: the Saku study. Hypertens Res 43 : 442-449. Link: https://go.nature.com/3luVBXa

19. Prasad Sah OS, Qing YX (2015) Associations Between Hyperuricemia and Chronic Kidney Disease: A Review. Nephrourol Mon 7: e27233. Link: https://bit.ly/3fw9W1L

20. Schlee S, Bollheimer LC, Bertsch T, Sieber CC, Härle P (2018) Crysta arthritides - gout and calcium pyrophosphate arthritis : Part 2: clinical features, diagnosis and differential diagnostics. Z Gerontol Geriatr 51: 579-584. Link: https://bit.ly/2TS94No

21. Yang L, Chang B, Guo Y, Wu X, Liu L (2019) The role of oxidative stressmediated apoptosis in the pathogenesis of uric acid nephropathy. Ren Fail 41 616-622. Link: https://bit.ly/3jp38Ea

22. Lytvyn Y, Bjornstad P, Lovshin JA, Singh SK, Boulet G, et al. (2019) Association between uric acid, renal haemodynamics and arterial stiffness over the natural history of type 1 diabetes. Diabetes Obes Metab 21: 1388-1398. Link: https://bit.ly/3A9TYCA

23. Fan S, Zhang P, Wang AY, Wang X, Wang L, et al. (2019) Hyperuricemia and its related histopathological features on renal biopsy. BMC Nephrol 20: 95. Link: https://bit.ly/3A9U2Ck

24. Johnson RJ, Nakagawa T, Jalal D, Sánchez-Lozada LG, Kang DH, et al. (2013) Uric acid and chronic kidney disease: which is chasing which? Nephrol Dial Transplant 28: 2221-2228. Link: https://bit.ly/3jiH2Dv

25. Braga TT, Foresto-Neto O, Camara NOS (2020) The role of uric acid in inflammasome-mediated kidney injury. Curr Opin Nephrol Hypertens 29: 423431. Link: https://bit.ly/3yuP820

26. Zhu P, Liu Y, Han L, Xu G, Ran JM (2014) Serum uric acid is associated with incident chronic kidney disease in middle-aged populations: a meta-analysis of 15 cohort studies. PLoS One 9: e100801. Link: https://bit.ly/3rQjt8S

27. Srivastava A, Kaze AD, McMullan CJ, Isakova T, Waikar SS (2018) Uric Acid and the Risks of Kidney Failure and Death in Individuals With CKD. Am J Kidney Dis 71: 362-370. Link: https://bit.ly/3lv0H5W

28. Oluwo O, Scialla JJ (2020) Uric Acid and CKD Progression Matures with Lessons for CKD Risk Factor Discovery. Clin J Am Soc Nephrol 16: 476-478. Link: https://bit.ly/3fx1FdZ

29. Doria A, Galecki AT, Spino C, Pop-Busui R, Cherney DZ, et al. (2020) Serum Urate Lowering with Allopurinol and Kidney Function in Type 1 Diabetes. $\mathrm{N}$ Engl J Med 382: 2493-2503. Link: https://bit.ly/3A6w3DW

30. Badve SV, Pascoe EM, Tiku A, Boudville N, Brown FG, et al. (2020) Effects of Allopurinol on the Progression of Chronic Kidney Disease. N Engl J Med 382: 2504-2513. Link: https://bit.ly/3jilWUM

31. Borgi L, McMullan C, Wohlhueter A, Curhan GC, Fisher ND, et al. (2017) Effect of uric acid-lowering agents on endothelial function: A randomized, double-blind, placebo-controlled trial. Hypertension 69: 243-248. Link: https://bit.ly/37yvfM1

32. Johnson RJ, Kivlighn SD, Kim YG, Suga S, Fogo AB (1999) Reappraisal of the pathogenesis and consequences of hyperuricemia in hypertension, cardiovascular disease, and renal disease. Am J Kidney Dis 33: 225-234. Link: https://bit.ly/3yALW4Y

Citation: Abbasi MT, Asghar MR, Bashir K, Hashmi MN (2021) Hyperuricemia in Renal patients: Treat or not to treat. Arch Clin Nephrol 7(1): $050-056$. DOI: https://dx.doi.org/10.17352/acn.000056 
33. Qayyum M, Butt B, Khan G (2019) hyperuricemia in pre-dialysis chronic kidney disease patients. A single centre experience. PAFMJ 69: 66-70. Link: https://bit.ly/3rQkOro

34. Tsai CW, Lin SY, Kuo CC, Huang CC (2017) Serum Uric Acid and Progression of Kidney Disease: A Longitudinal Analysis and Mini-Review. PLoS One 12 e0170393. Link: https://bit.ly/3frq4Im

35. Hsu SP, Pai MF, Peng YS, Chiang CK, Ho TI, et al. (2004) Serum uric acid levels show a 'J-shaped' association with all-cause mortality in haemodialysis patients. Nephrol Dial Transplant 19: 457-462. Link: https://bit.ly/3fwcLQp

36. Feng S, Jiang L, Shi $Y$, Shen $H$, Shi $X$, et al. (2013) Uric acid levels and all-cause mortality in peritoneal dialysis patients. Kidney Blood Press Res 37: 181-189. Link: https://bit.ly/3ytAdW0

37. Kadkhodaee M, Hemmati M, Zahmatkesh M, Ghaznavi R, Mirershadi F, et al. (2008) Assessment of Plasma Antioxidant Status in Hemodialysis Patients. Therapeutic Apheresis and Dialysis 12: 147-151. Link: https://bit.ly/2TUmcSj

38. Robson M, Oreopoulos DG, Izatt S, Ogilvie R, Rapoport A, et al. (1978) Influence of exchange volume and dialysate flow rate on solute clearance in peritoneal dialysis. Kidney Int 14: 486-490. Link: https://bit.ly/3lv000I

39. Latif W, Karaboyas A, Tong L, Winchester JF, Arrington CJ, et al. (2011) Uric acid levels and all-cause and cardiovascular mortality in the hemodialysis population. Clin J Am Soc Nephrol 6: 2470-2477. Link: https://bit.ly/3ynUnRn

40. Beberashvili I, Sinuani I, Azar A, Shapiro G, Feldman L, et al. (2015) Serum uric acid as a clinically useful nutritional marker and predictor of outcome in maintenance hemodialysis patients. Nutrition 31: 138-147. Link: https://bit.ly/3imJKbT

41. Clive DM (2000) Renal transplant-associated hyperuricemia and gout. J Am Soc Nephrol 11: 974-979. Link: https://bit.ly/3jnuQBu

42. Lin HY, Rocher LL, McQuillan MA, Schmaltz S, Palella TD, et al. (1989) Cyclosporine-induced hyperuricemia and gout. N Engl J Med 321: 287-292. Link: https://bit.ly/3Ce9qPN

43. Noordzij TC, Leunissen KM, Van Hooff JP (1991) Renal handling of urate and the incidence of gouty arthritis during cyclosporine and diuretic use. Transplantation 52: 64-67. Link: https://bit.ly/3xss6aJ

44. Bellomo G (2015) Asymptomatic hyperuricemia following renal transplantation World J Nephrol 4: 324-329. Link: https://bit.ly/3xshJUu

45. Weng SC, Shu KH, Tarng DC, Cheng CH, Chen $\mathrm{CH}$, et al. (2014) Uric acid is highly associated with kidney allograft survival in a time-varying analysis. Transplant Proc 46: 505-510. Link: https://bit.ly/3rQS3Qa

46. Akgul A, Bilgic A, Ibis A, Ozdemir FN, Arat Z, et al. (2007) Is uric acid a predictive factor for graft dysfunction in renal transplant recipients? Transplant Proc 39 1023-1026. Link: https://bit.ly/3lvz3G0

47. Mazali FC, Mazzali M (2011) Uric acid and transplantation. Semin Nephrol 31 466-471. Link: https://bit.ly/2VwEWaY

48. Zhang W, Doherty M, Bardin T, Pascual E, Barskova V, et al. (2006) EULAR evidence based recommendations for gout. Part II: Management. Report of a task force of the EULAR Standing Committee for International Clinical Studies Including Therapeutics (ESCISIT). Ann Rheum Dis 65: 1312-1324. Link: https://bit.ly/3ltqjjv

49. Dessein PH, Shipton EA, Stanwix AE, Joffe BI, Ramokgadi J (2000) Beneficial effects of weight loss associated with moderate calorie/carbohydrate restriction, and increased proportional intake of protein and unsaturated fat on serum urate and lipoprotein levels in gout: a pilot study. Ann Rheum Dis 59 : 539-543. Link: https://bit.ly/3Cpjt4K
50. Goicoechea M, de Vinuesa SG, Verdalles U, Ruiz-Caro C, Ampuero J, et al. (2010) Effect of allopurinol in chronic kidney disease progression and cardiovascular risk. Clin J Am Soc Nephrol 5: 1388-1393. Link: https://bit.ly/2WlzwtR

51. Kao MP, Ang DS, Gandy SJ, Nadir MA, Houston JG, et al. (2011) Allopurinol benefits left ventricular mass and endothelial dysfunction in chronic kidney disease. J Am Soc Nephrol 22: 1382-1389. Link: https://bit.ly/3A9MHm5

52. Talaat KM, el-Sheikh AR (2007) The effect of mild hyperuricemia on urinary transforming growth factor beta and the progression of chronic kidney disease. Am J Nephrol 27: 435-440. Link: https://bit.ly/3xlxvAn

53. Whelton A, Macdonald PA, Zhao L, Hunt B, Gunawardhana L (2011) Rena function in gout: long-term treatment effects of febuxostat. J Clin Rheumato 17: 7-13. Link: https://bit.ly/3A84PwD

54. Whelton A, MacDonald PA, Chefo S, Gunawardhana L (2013) Preservation of renal function during gout treatment with febuxostat: a quantitative study. Postgrad Med 125: 106-114. Link: https://bit.ly/3ynVtMZ

55. Kimura K, Hosoya T, Uchida S, Inaba M, Makino H, et al. (2018) Febuxostat Therapy for Patients With Stage 3 CKD and Asymptomatic Hyperuricemia: A Randomized Trial. Am J Kidney Dis 72: 798-810. Link: https://bit.ly/3fum4QK

56. Choi H, Neogi T, Stamp L, Dalbeth N, Terkeltaub R (2018) New Perspectives in Rheumatology: Implications of the Cardiovascular Safety of Febuxostat and Allopurinol in Patients With Gout and Cardiovascular Morbidities Trial and the Associated Food and Drug Administration Public Safety Alert. Arthritis Rheumatol 70: 1702-1709. Link: https://bit.ly/3inOMot

57. Vargas-Santos AB, Neogi T (2017) Management of Gout and Hyperuricemia in CKD. Am J Kidney Dis 70: 422-439. Link: https://bit.ly/3jm5CmX

58. Hung SI, Chung WH, Liou LB, Chu CC, Lin M, et al. (2005) HLA-B*5801 allele as a genetic marker for severe cutaneous adverse reactions caused by allopurinol. Proc Natl Acad Sci U S A. 102: 4134-4139. Link: https://bit.ly/3rTMmB3

59. Strilchuk L, Fogacci F, Cicero AF (2019) Safety and tolerability of available urate-lowering drugs: a critical review. Expert Opin Drug Saf 18: 261-271. Link: https://bit.ly/3AdCyVF

\section{Discover a bigger Impact and Visibility of your article publication with} Peertechz Publications

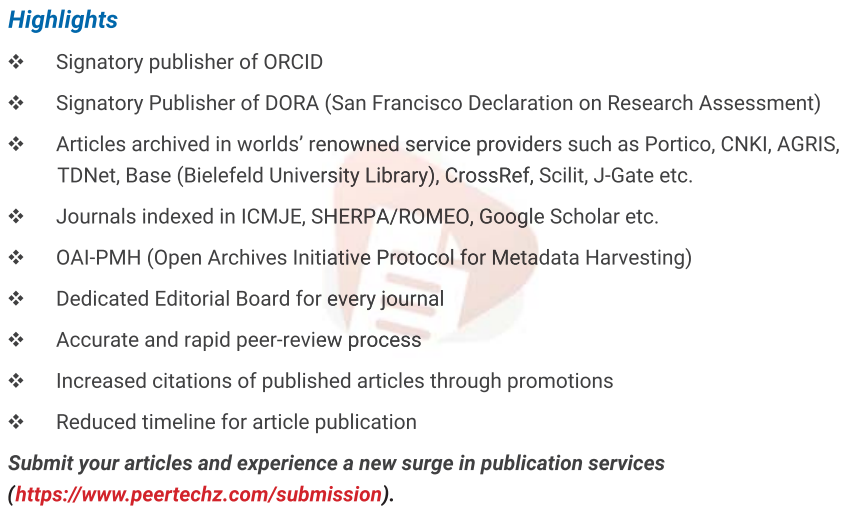

Copyright: @ 2021 Abbasi MT. This is an open-access article distributed under the terms of the Creative Commons Attribution License, which permits unrestricted use, distribution, and reproduction in any medium, provided the original author and source are credited.

Citation: Abbasi MT, Asghar MR, Bashir K, Hashmi MN (2021) Hyperuricemia in Renal patients: Treat or not to treat. Arch Clin Nephrol 7(1): 050-056. DOI: https://dx.doi.org/10.17352/acn.000056 